\title{
Role of stem/progenitor cells in reparative disorders
}

\author{
Thavaneetharajah Pretheeban, Dario R Lemos, Benjamin Paylor, Regan-Heng Zhang and Fabio M Rossi*
}

\begin{abstract}
Adult stem cells are activated to proliferate and differentiate during normal tissue homeostasis as well as in disease states and injury. This activation is a vital component in the restoration of function to damaged tissue via either complete or partial regeneration. When regeneration does not fully occur, reparative processes involving an overproduction of stromal components ensure the continuity of tissue at the expense of its normal structure and function, resulting in a "reparative disorder". Adult stem cells from multiple organs have been identified as being involved in this process and their role in tissue repair is being investigated. Evidence for the participation of mesenchymal stromal cells (MSCs) in the tissue repair process across multiple tissues is overwhelming and their role in reparative disorders is clearly demonstrated, as is the involvement of a number of specific signaling pathways. Transforming growth factor beta, bone morphogenic protein and Wnt pathways interact to form a complex signaling network that is critical in regulating the fate choices of both stromal and tissue-specific resident stem cells (TSCS), determining whether functional regeneration or the formation of scar tissue follows an injury. A growing understanding of both TSCs, MSCs and the complex cascade of signals regulating both cell populations have, therefore, emerged as potential therapeutic targets to treat reparative disorders. This review focuses on recent advances on the role of these cells in skeletal muscle, heart and lung tissues.
\end{abstract}

Keywords: Fibrosis, Fatty degeneration, Heterotopic ossification, Tissue specific stem cells, Mesenchymal stromal cells, TGF $\beta$, BMP, Wnt

\section{Review} Introduction

Tissue repair post-injury or during disease culminates in either complete restoration of tissue integrity, defined here as regeneration, or in a process that leads to the generation of stromal structures that replace functional tissue. These structures, while vital in ensuring tissue continuity, do not support, and in some instances even interfere with, tissue or organ function. The establishment of these stromal scars is referred herein as "repair", and conditions in which they become predominant are called "reparative disorders". This term encompasses diseases or symptoms exhibited during the repair process of damaged tissues that have been described in the literature since the early nineteenth century, including adipocyte accumulation (fatty degeneration), ectopic bone formation and fibrous tissue deposition [1-3]. In the

\footnotetext{
* Correspondence: fabio@brc.ubc.ca

The Biomedical Research Centre, The University of British Columbia, Vancouver, BC V6T 1Z3, Canada
}

(c) 2012 Pretheeban et al.; licensee BioMed Central Ltd. This is an Open Access article distributed under the terms of the

context of mammalian biology, tissue regeneration is an essential process for restoring structure and function of traumatized organs. Regeneration of tissues is typically accompanied by acute or chronic inflammation caused by the disease or trauma, and involves the coordinated interaction among multiple cell types, including tissue specific stem/ progenitor cells (TSCs), mesenchymal stromal cells (MSCs) and immune cells. Many of the same cell types involved in regeneration also contribute to repair, suggesting that aberrant environmental cues and alterations of the signaling networks between these cells are central to the establishment of reparative disorders [4].

Several sources have been proposed for the progenitors involved in reparative disorders, including local sources, such as the damaged tissues themselves, and systemic sources, such as the bone marrow [5]. Locally, both tissue specific stem cells and ubiquitous mesenchymal and endothelial progenitors have been implicated in 
the development of the cellular effectors of repair: fibrotic matrix producing cells, adipocytes and osteocytes. Systemically, a role has been proposed for bone marrow derived cells reaching the repairing tissues through the bloodstream. Here, we review the evidence concerning these different types of stem cells and, in particular, the role of TSCs and MSCs in reparative disorders. We also provide an overview of the signaling pathways mediating their interactions.

The three most commonly occurring outcomes of reparative disorders are fibrosis, fatty degeneration and heterotopic ossification. Fibrosis is a defining characteristic in most reparative disorders and can take place in nearly every tissue. In fibrosis, damaged structures are gradually replaced by collagen-rich connective tissue resulting in anatomical anomalies as well as reduced functional capacities. The poorly defined fibroblast or myofibroblast, the effector cell components of connective tissue, is thought to be responsible for producing excess collagen and other extracellular matrix (ECM) proteins [6]. These same processes, however, also take place during normal regeneration, and are likely to be critical for its success. Another type of common reparative disorder is the accumulation of fat in damaged tissues leading to "fatty degeneration" and loss of function [4-6]. Usually, fat is found in newly formed adipocytes infiltrating the tissue, most often associated with concurrent fibrotic matrix deposition, and in these cases it is clearly associated with injuries and defective repair processes [7-9]. Finally, heterotopic ossification, also known as ectopic bone formation, is another frequent reparative complication that takes place in the context of excessive trauma, surgery, wounds and burns. While non-hereditary and hereditary extra-skeletal bone formation is discussed in detail elsewhere $[10,11]$, here we will focus only on the source of osteogenic cells in aberrant repair processes.

\section{Tissue resident stromal cells}

In the adult organism, fibroblasts, adipocytes and osteocytes are thought to be generated from the same multipotent mesenchymal progenitors. These progenitors, officially termed mesenchymal stromal cells (MSCs) in a positional paper from the International Society for Cellular Therapeutics [12] continue to be referred to as mesenchymal stem cells [13], despite the lack of clear experimental evidence supporting their ability to selfrenew and satisfy the most basic definition of a stem cell [14]. The accumulation of these mature cell types in tissues that have failed to properly regenerate suggests that alterations in the function of MSCs may represent a common thread underlying reparative disorders [15]. While a minimal set of markers defining an MSC has been agreed upon [12], expression of these markers is clearly heterogeneous both in vivo and in vitro and does not currently allow their prospective purification. In addition, while MSCs retain a similar developmental potential in most tissues, the expression of specific markers may vary depending on their specific anatomical location, a reality that has hindered the proper characterization of stromal progenitors. To date, the most reliable characteristic of stromal progenitors is the ability to produce fibroblastic colonies and, under the appropriate culture conditions, to differentiate in adipocytes, chondrocytes and osteogenic cells. The generation of additional cell types, such as endothelium and skeletal muscle, has been reported, but no consensus exists on whether such expanded developmental potential is actually observed in physiological conditions. Indeed, in the absence of specific markers to identify them in situ, elucidating the role of MSCs in the maintenance of differentiated tissues, such as bone and fat depots in vivo, has been difficult and their importance is as yet unclear. Another role for this cell type that has emerged over the years has spurred their therapeutic exploitation in ex vivo delivery approaches, and lies in their ability to provide trophic support to multiple cell types following tissue damage.

Almost all postnatal organs and tissues contain MSCs [16], and the list of resident stromal cells involved in tissue homeostasis and repair now includes multiple cell types, such as pericytes in multiple tissues [17,18], fibroadipogenic progenitors (FAPs) in muscle and adipose tissues [19,20], adipose precursor cells in skin [21] and myo-fibroblasts in the liver, kidneys and lungs [22]. It is unclear whether these are truly distinct cell types, or if they, rather, represent a diffused stromal progenitor system comprised of cells that display different propensity to spontaneously differentiate along specific lineages, but possess a common underlying developmental potential that can be revealed by exposure to the appropriate stimuli. In addition to these ubiquitous progenitors, tissue fibroblasts have also been proposed to arise from circulating bone marrow cells or, in specific organs, from epithelial-mesenchymal transition (EMT) (see reviews $[23,24])$; the controversial evidence supporting these claims will be discussed below. The multiple proposed sources of fibrogenic cells in adult life are schematically depicted in Figure 1.

Despite the uncertainties and controversies stemming from their incomplete characterization, recent literature clearly supports a role for MSCs not only in immunomodulation, trophic support, angiogenesis and other processes associated with successful tissue regeneration, but also in reparative disorders, such as fibrosis and fatty degeneration [25-27]. Here we discuss recent advances on the role of MSCs in skeletal and cardiac muscle as well as lung reparative disorders. 


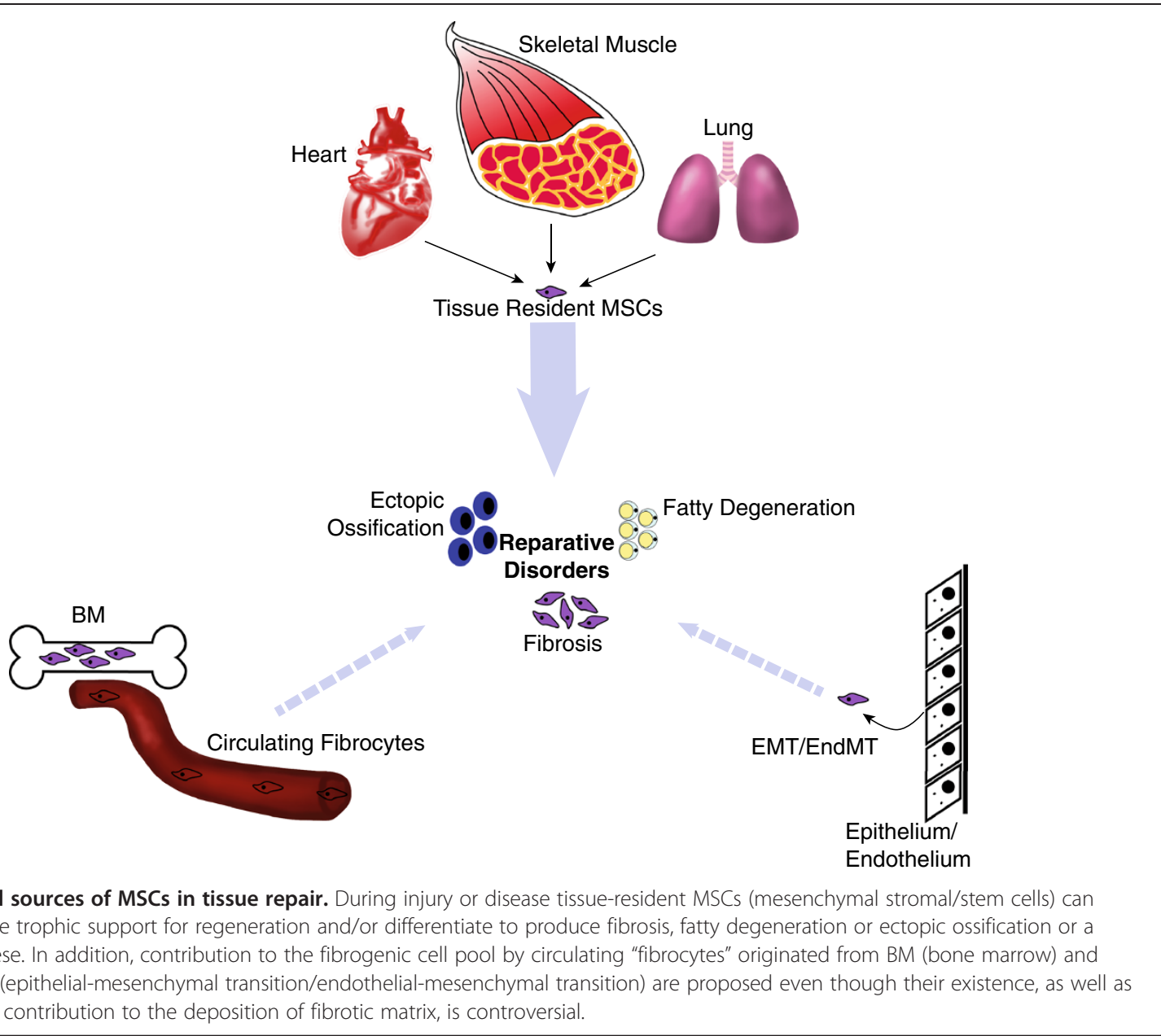

The role of tissue-resident MSCs and TSCs in reparative disorders

Skeletal muscle - an ideal regenerative/degenerative model system

Skeletal muscle, like many other organs, contains stromal cells that are active following injury in both healthy animals and disease models. In addition, stromal cells are believed to play an essential role in muscle development [28]. These stromal cells are found in the muscle interstitium as well as associated with blood vessels (Figure 2). While often found in a perivascular position, they have been reported not to express typical pericytic markers, such as NG2 [29,30]. In mice, these cells are capable of spontaneously differentiating along the fibrogenic and adipogenic lineages in vitro, and have, therefore, been provisionally called fibro-adipogenic progenitors (FAPs) [19]. FAPs can be isolated as CD $45^{-} / \mathrm{CD} 31^{-} / \alpha 7$ $/ \mathrm{CD} 4^{+} / \mathrm{Sca}-1^{+} / \mathrm{PDGFR}^{+}$cells. Cells expressing fibroblast markers (ER-TR7/FSP1/ $\alpha$ SMA) or adipogenic markers, such as perilipin, arise from individual multipotent progenitors contained in this population. We and others $[19,31]$ have further demonstrated that the fate of these progenitors is heavily dependent on the environment within which they reside. This local microenvironment dictates whether these cells provide trophic support to satellite cells, the endogenous myogenic stem cells, to yield complete regeneration of injured muscle or whether they generate the components of the fibro-fatty tissue infiltrates often found in degenerating muscle tissue. A role for these cells in the efficient regeneration of muscle is also supported by depletion experiments relaying on the expression of CRE recombinase under the control of the transcription factor Tcf4 [28]. This approach led to the depletion of only about $40 \%$ of the cells, and highly efficient deletion of stromal progenitors has yet to be achieved in any organ. More recently, also in support of a paracrine effect of MSCs, Lavasani et al. [32] reported that muscle derived stem/progenitor cells (MDSPCs), essentially stromal cells isolated from young mice, were able to improve degenerative changes in aged mice and observed a correlation between MDSPC abundance and better muscle fiber maturation post injury.

Skeletal muscle resident FAPs are quiescent in healthy tissue, but quickly respond to damage by entering 


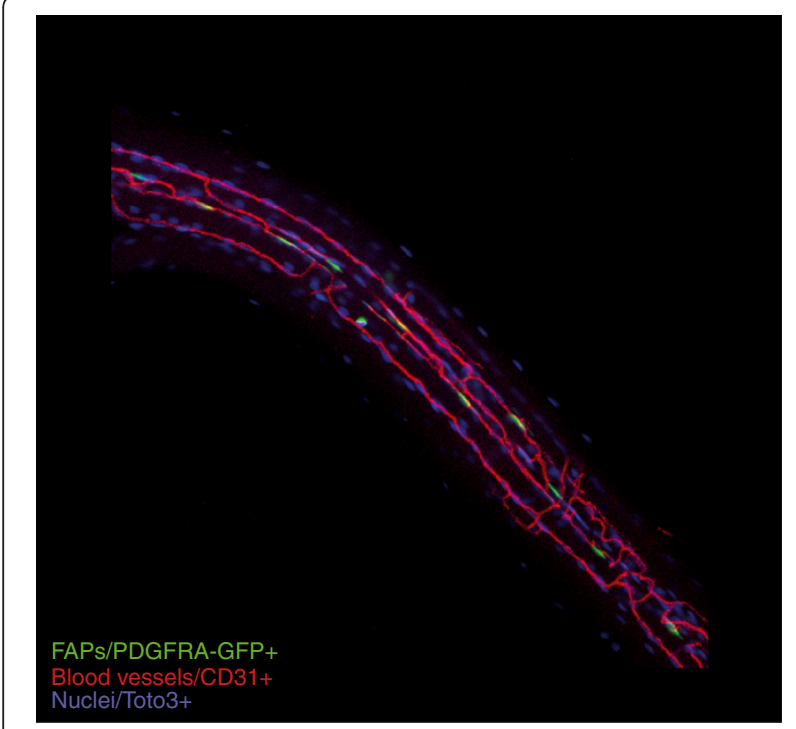

Figure 2 Fibro/adipogenic progenitors (FAPs) in skeletal muscle. Confocal image of a cluster of muscle fibers harvested from non-damaged muscle showing the relationship between mesenchymal progenitors expressing nuclear GFP under the control of the PDGFRa locus and fiber-associated blood vessels positive for CD31 (red). Nuclei are stained blue.

proliferation and expanding to infiltrate the extracellular space between myofibers, where they presumably carry out their trophic support function. Following this period of expansion, and at a time in which myogenic progenitors are differentiating to regenerate myofibers, the excess FAPs generated during the expansion phase quickly disappear and the cells return to quiescence. This, however, is not the case in degenerative disease or during aging. In situations where regeneration fails, FAPs persist and generate fibrous/fatty tissue that, while maintaining structural integrity, hinders function and subsequent regeneration $[33,34]$. It is important to note that FAPs have been reported to be the only source of collagen producing cells in regenerating skeletal muscle [35], clearly pointing to these cells as the main origin of fibrosis. While strong support exists for both the trophic role of FAPs and their role on tissue degeneration, the signals regulating their growth, survival and differentiation are still unknown. As these signals represent promising therapeutic targets for the treatment of acute and chronic injuries, they are the objects of intense investigation [36].

\section{Role of skeletal muscle derived MSCs in heterotopic ossification}

Heterotopic ossification is a common finding following severe or repeated soft tissue injuries, usually associated with fibrotic or fibro-fatty degeneration. The involvement of MSC-like progenitors in this process is supported by observations in war-traumatized patients, whose muscle are found to contain cells capable of producing fibroblastic colonies and to give rise to osteoblasts, adipocytes and/or chondrocytes [37-39]. Presumably in these instances, while a subset of local mesenchymal progenitors proliferate and differentiate into fibroblasts producing fibrotic matrix, some adopt a different lineage commitment and become osteoprogenitors. They, in turn, differentiate into osteoblasts, eventually resulting in ectopic bone formation [40]. Indeed, while FAPs were originally described as bipotent progenitors due to their spontaneous differentiation along the fibrogenic and adipogenic lineages, recent evidence strongly supports their role in ectopic bone formation. Following this, early reports suggested that these cells could generate alkaline phosphatase positive cells [31]. More recently, [41] reported that $\mathrm{CD} 31^{-} / \mathrm{CD} 45^{-} / \mathrm{PDGFRa}^{+} / \mathrm{Sca}-1^{+} / \mathrm{Tie}^{+}$progenitors from skeletal muscle could generate cells expressing the osteoprogenitor marker osterix when exposed to bone morphogenic protein 2 (BMP2) in vitro or in a transplantation setting. In addition, lineage-tracing experiments showed that these cells were the main source of ectopic cartilage and bone when BMP2 was delivered to skeletal muscle in vivo [41]. In these experiments, not all osteogenic cells expressed the Tie2-CRE activated lineagetracing marker. However, it is unclear whether this reflects inefficient CRE mediated recombination or the participation of Tie2 negative cells in this process. Supporting our previous results, without addition of $\mathrm{BMP} 2$, these cells failed to adopt the fate of cartilage or bone, demonstrating that environmental cues are dictating the destiny of these progenitors and, thereby, the outcome of wound healing.

\section{Role of tissue-specific stem cells in skeletal muscle degeneration}

Although the role of MSCs in the development of reparative disorders in skeletal muscle has been clearly demonstrated, there is also evidence implicating a role of TSCs in modulating aberrant repair processes in this organ. The importance of the principal stem cell in adult myogenesis, the satellite cell, in regeneration is well established, but the relationship between these stem cells and tissue degeneration is much more complex and not well understood. Satellite cells reside between the myofibers and basement membrane of the muscle bundle [42] and unlike tissues that experience constant wear and tear, these TSCs are normally quiescent/stable, and are not activated until prompted by injury. Quiescent satellite cells are identified by their expression of Pax7, a paired homeobox transcription factor partly responsible for survival and specification of the myogenic cell lineage [43]. Although an excellent marker of all satellite cells in the wild-type adult, Pax7 is only required during the neonatal stage for satellite cell maintenance, 
proliferation and differentiation $[44,45]$. Following traumatic myofiber damage or temporal progression of myopathy, these satellite cells become activated and readily proliferate, differentiate and give rise to myoblasts, which fuse with damaged myofibers or form new myofibers.

Fibrosis is often associated with the impairment of stem cell populations in tissues, which are observed in many disease conditions. In skeletal muscle, fibrosis was considered to be caused by dysfunctional satellite cells. Using a murine model of muscular dystrophy (MDX), Alexakis and others reported the expression of collagen in primary myoblasts [46]. They have also found collagen expression in $\mathrm{C} 2 \mathrm{C} 12$, a myoblast cell line. These findings indicate that satellite cells and transitionally amplifying myoblasts might deviate from their myogenic process to lead fibrosis-dominated degeneration. Furthermore, Keller [47] has suggested that the dysregulation of satellite cells during neonatal muscle growth is linked to rhabdomyosarcoma, a rare form of connective tissue tumor. Recently, in a mouse model of spinal muscular atrophy, mutation in the survival of motor neuron (SMN) gene is shown to affect the satellite cell's intrinsic differentiation capacity, leading to a reduced efficiency in myotube formation [48]. Moreover, the conversion of satellite cells from a myogenic lineage to a fibrogenic lineage is documented in aging [49] and suggested that in aged mice, activation of the canonical Wnt signaling pathway is responsible for a pro-fibrotic phenotype. Other cases of fibrogenesis in myoblasts are also reported [50,51]. In addition, a recent study examining the stem cell function in aged people demonstrates that an age-related impairment of satellite cells is associated with increased co-localization of myostatin in satellite cells of type II myofibers [52]. Thus, tissue-specific stem cells responsible for regeneration, such as satellite cells in skeletal muscle, may also be involved in degenerative processes; however, whether the triggers for degeneration are cell autonomous or environmental influences, such as niche factors, is unknown.

\section{Tissue-resident MSCs reside in the heart}

In mammals, cardiac damage is not followed by the complete replacement of lost cellular components but is rather defined by a relatively minor capacity for regeneration and far more robust reparative response. Lacking an ability to regenerate, the formation of a scar in a timely manner following cardiac damage or during cardiac disease is critical in allowing continued organ functionality. Although there is a growing body of evidence demonstrating that the heart harbors its own population of TSCs, the cardiac stem cells [37,38], which account for the limited regenerative capacity of this organ, recent evidence has suggested that, similar to other organs, its repair processes may be governed by a cardiac-resident population of MSCs. The identification and elucidation of developmental origins of a novel population of stromal progenitors present within the myocardium has recently been reported [39], and further been demonstrated to be highly similar to MSCs derived from other tissues [40]. This population of cells contains all the fibroblastic colony-generating progenitors in the tissue, and was isolated based on markers essentially identical to those expressed by stromal progenitors in skeletal muscle (Sca-1 ${ }^{+} / \mathrm{PDGFRa}^{+} / \mathrm{CD}^{-} 1^{-}$) and was further shown to originate from the pro-epicardium. Expression of accepted markers of MSCs (CD44, CD90, CD29 and CD105) was confirmed on these cells, which also exhibited long-term growth potential in culture and were reported to possess the ability to form multiple mesodermal lineages (cardiomyocytes, endothelium, smooth muscle, adipocytes, cartilage and bone). As in skeletal muscle, in adult mice these cells occupy a perivascular, adventitial niche. A wider developmental potential encompassing elements of all germ layers has been reported for these cells upon co-transplantation with teratoma-forming ES cells, although the fact that fusion-induced reprogramming was not excluded in these experiments is a caveat. While the response of these cells to acute or chronic damage has yet to be analyzed in detail, it seems likely that similar to their phenotypically identical counterparts in skeletal muscle and other tissues $[35,53]$, cardiac Sca1 ${ }^{+}, \mathrm{PDGFR \alpha}^{+}$cells are a main source of fibrogenic cells in pathological cardiac fibrosis and that they participate in the formation of post-infarction scars.

\section{Tissue-resident MSCs in the lung}

In lungs, an anti-fibrotic role has been reported for exogenously delivered bone marrow derived MSCs, which likely rests on their ability to secrete trophic factors during normal regeneration. However, in keeping with what is reported in other tissues, lung derived/resident MSCs (LR-MSCs) have also been associated with fibrogenesis and aberrant tissue repair in lung injuries, such as transplantation surgery [54]. Lama and others first isolated LR-MSCs from the bronchoalveolar lavage fluid of lung transplantation patients [55]. These cells exhibited plastic adherence, formation of colony forming unit fibroblasts (CFU-Fs), multipotency and expression of a combination of typical MSC surface markers CD44, CD73, CD90 and CD105 [55,56]. In most of the studies in which LR-MSCs exhibited a progressive fibrotic phenotype, investigators have used chronic injury models. Studies describing a positive role for exogenous MSCs, however, mainly relied on acute injury models, supporting the notion that these cells may play different roles in different settings.

It has been suggested that bi-directional crosstalk between stromal progenitors and cells involved in immune 
responses may control both the fate and function of LRMSCs and vice versa. Jun and others recently characterized a population of lung-derived stromal cells (Hoechst ${ }^{\mathrm{dim}}$ / CD45 ), which attenuated bleomycin-induced lung fibrosis and modulated local immune function by inhibiting antigen driven proliferative responses of effector $\mathrm{T}$ cells and decreasing the number of lymphocytes and granulocytes in bronchoalveolar fluid when transplanted [57]. These cells were distinct from lung fibroblasts in terms of gene expression, showing decreased expression of genes associated with inflammation, myofibroblast specification and extracellular matrix production. Unfortunately, as in other tissues, the heterogeneity of methods and markers used for the definition and characterization of LR-MSCs makes it very difficult to compare different studies and reach a consensus on their role at this time.

Apoptosis of stromal cells has been proposed to be one of the main mechanisms leading to the resolution of fibrosis during normal wound healing in many organs, and it is believed that in progressive fibrotic lesions, MSCs and their progeny escape its induction, leading to increased matrix deposition. Proposed roles of macrophages, $\mathrm{T}$ cells and the inflammatory microenvironment in general in regulating the survival of LR-MSCs in airway and interstitial pulmonary fibrosis are reviewed elsewhere [58].

\section{Alternative cellular sources for tissue-effector myofibroblasts}

The progression from regeneration to repair invariably involves the development of fibrosis, defined as an excessive deposition of extracellular matrix. The principal cell type known to be involved in this process is an activated fibroblast derivative called a myo-fibroblast. The transition towards fibrosis was traditionally thought to involve expansion of stromal progenitors and subsequent differentiation into myo-fibroblasts, defined by increased synthesis of ECM proteins, such as fibrillar collagens and fibronectin as well as de-novo expression of alphasmooth muscle actin. Although the importance of myofibroblasts in the development of fibrosis is generally accepted, there continues to be a significant debate whether alternative cellular sources, rather than differentiation from tissue-resident mesenchymal progenitors, exist for myofibroblasts.

The notion that collagen-producing myofibroblasts arise solely from the proliferation and differentiation of tissue-resident cells began to be questioned in the mid1990s when two alternative cellular sources were proposed: (1) epithelial cells undergoing epithelial-to-mesenchymal transition (EMT) [59] and (2) circulating bone-marrow derived fibrocytes [5]. These concepts have important implications towards both the theoretical cellular processes underlying the development of fibrosis, and also the development of novel therapeutics to abrogate the process. Despite a wealth of literature supporting both theories, a growing number of recent studies employing much more rigorous lineage tracing analysis have cast a significant degree of doubt on the notion that fibrogenic cells arise from sources outside of tissue-resident MSCs.

\section{Epithelial-to-mesenchymal transition (EMT)}

Long known to be involved in metazoan embryogenesis, recent studies provided evidence that epithelial mesenchymal transition can also occur in adult tissues during the development of fibrosis as well as the progression and metastasis of cancer. Although the prevalence, as well as importance, of EMT in both embryogenesis and cancer is rarely disputed, a growing body of recent evidence has led many to reject the notion that EMT plays a role in solid organ regeneration and repair [60-62]. Recent use of more rigorous lineage tracing tools have strongly called into question the ability of epithelial cells to transition into collagen-producing mesenchymal cells during repair processes in numerous tissues, such as the kidneys [63-65], liver [66-68] and lungs [69]. There is a growing consensus that although EMT can be achieved in vitro through transforming growth factor (TGF) $\beta 1$ treatment, this process does not make any significant contribution in vivo during tissue repair. Additionally, research attributing EMT as an important source of myofibroblasts have widely used the marker FSP1 (also known as S100A4) as a marker of epithelium-derived fibroblasts, which has repeatedly been shown to not label collagen producing cells in some tissues [65] and to lack specificity by labeling other cells, such as monocytes, macrophages, neutrophils and granulocytes [70]. Such critiques towards the field of EMT in tissue repair can also be applied to other processes, such as endothelial-to-mesenchymal transition (EndMT), which has used similarly questionable methods to demonstrate EndMT as an important source of tissue-effector myofibroblasts [71]. Further, additional doubt can be cast on EMT and EndMT data due to recent reports which demonstrate that Cre drivers previously thought to exclusively label epithelial or endothelial lineages (for example, Tie2) do not possess the necessary specificity to conclude that progeny labeled by these markers are exclusively derived from the epithelium or endothelium [41].

\section{Fibrocytes}

Circulating bone marrow derived mesenchymal progenitors, termed fibrocytes, have been proposed as a second alternative source of collagen-producing myo-fibroblasts in situations of tissue repair [5]. First described in 1994 [72], fibrocytes have classically been identified using a combination of hematopoietic markers CD34 and CD45, 
as well as the mesenchymal markers vimentin and collagen 1, although numerous further markers have been added in recent years [73]. Although there continues to be numerous studies published describing the role of circulating cells in the development of fibrosis, a number of recent reports have begun to call into question this model. Central to arguments that oppose the role of fibrocytes in fibrosis has been that much of the data supporting this model is based on phenotypical identification of fibroblasts of bone marrow derived origin, rather than characterization of the functional role these cells have in the development of tissue fibrosis. Following this, more recent studies employing more sophisticated techniques, such as genetic polymorphisms of collagen proteins in sex mismatched transplant recipients [74], as well as more specific collagen transgenics [75], have provided compelling evidence that, in numerous types of tissue repair, collagen-producing myofibroblasts arise solely from cells residing within the organ. Additionally, it should be noted that the same problematic reagents employed to identify the role of EMT in fibrosis, such as fibroblast markers of dubious specificity (for example, FSP1, vimentin) are also prevalent in a number of studies examining the role of fibrocytes [71].

\section{Signaling in MSCs}

Given their relevance in tissue regeneration, MSCs must maintain fluid communication with their surroundings. Indeed, a variety of stimuli, including physical and chemical signals originating in both the niche and the systemic environment, convey information to the MSCs. Integration of such signals can result in alteration of the otherwise quiescent state of MSCs, eliciting a sequence of fate choices that may include proliferation, selfrenewal, migration, differentiation and cell death. In the absence of tissue damage and inflammation, systemic and metabolic cues can modulate the activity of stem cells under what can be regarded as homeostatic conditions [76]. Upon tissue damage, however, acute signals become the leading cues directing MSC activity. The combination of systemic and acute stimuli eventually drives the fate choice of MSC-derived progenitors into lineages that will contribute to the regeneration of the tissue. Under pathological conditions, however, aberrant signaling can lead to the development of ectopic cell types that contribute to the degeneration of the damaged tissue. In addition to the better-characterized pathways, such as FGF, PDGF and EGF, current advances in the study of the TGF $\beta$, BMP and Wnt signaling cascades have disclosed a critical role for these factors in the regulation of mesenchymal stem cell behavior during tissue regeneration. The fact that the three pathways interact closely, partly through shared intracellular components, provides a number of interesting signaling crossroads that will be worth exploring in further depth. A summary of these signaling pathways and their effects is illustrated in Figure 3.

TGF $\beta$, a member of the TGF $\beta$ superfamily, constitutes one of the major regulators of mesenchymal fate choice in postnatal life [77]. TGF $\beta$ signaling supports the early stages of chondroblastic and osteoblastic differentiation, while acting as an inhibitor of the advanced stages of osteoblast differentiation [78]. TGF $\beta$ inhibits adipogenic differentiation [79] through a route that involves interaction between the canonical complex SMAD3/SMAD4 with the transcriptional regulator C/EBP [80].

TGF $\beta$ signaling plays a pivotal role in both dermal homeostasis and hair follicle regeneration, where TGFB2 produced by the dermal papillae of the follicles drives hair follicle stem cells out of quiescence and activates them during the telogen-to-anagen transition [81]. Timely TGF $\beta$ release is critical for the initial stages of wound healing. Following damage, TGF $\beta 1,-2$ and -3 are secreted by various cell types, including platelets, fibroblasts, macrophages and keratinocytes. TGF $\beta$ signaling stimulates the temporary production of extracellular matrix (ECM) by fibroblasts and attracts macrophages that will participate in the inflammatory response [82]. Aberrant TGF $\beta$ signaling in the dermis, on the other hand, elicits excessive ECM deposition, fibrosis and scar formation that can lead to the formation of skin keloids [82]. In addition to its effect on fibroblasts and macrophages, TGF $\beta$ stimulates proliferation and sphere colony formation in skin-derived precursors (SKPs) in vitro, without altering their multipotency [83]. Excessive TGF $\beta$ production also correlates with skeletal muscle (SM) fibrosis [84], a characteristic feature of Duchenne muscular dystrophy [85]. Within SM, TGF $\beta$ targets mesenchymal $\mathrm{Lin}^{-} / \alpha 7^{-} / \mathrm{Sca}-1^{+} / \mathrm{PDGFRa}^{+}$progenitor cells that reside in the interstitial mesenchyme and can differentiate into collagen-producing fibroblasts [35]. Importantly, the same progenitor population can adopt the adipogenic lineage upon SM degenerative damage, leading to intramuscular ectopic fat accumulation [19,20,31].

The TGF $\beta$ family of signaling proteins is also important in the maintenance and expansion of bone and cartilage, largely through BMP proteins and TGF $\beta$ itself [76]. TGF $\beta$ promotes the proliferation, early differentiation and lineage commitment of bone progenitors through Smad2/3 and TAK1-MKK-p38 signaling [78]. Members of the BMP: BMP-2, 4, 5, 6 and 7 constitute osteogenic inducers. In particular, BMP-2 expression is sufficient for full osteogenic commitment, and loss of BMP-2 leads to impaired osteogenesis [86]. BMP-2 signals through type -I and -II BMP receptors and through the ALK2 receptor, leading to the activation of the Smad1/5/8 canonical pathway $[87,88]$. Following TGF $\beta$ and BMP induction, Smad and MAPK signals converge 


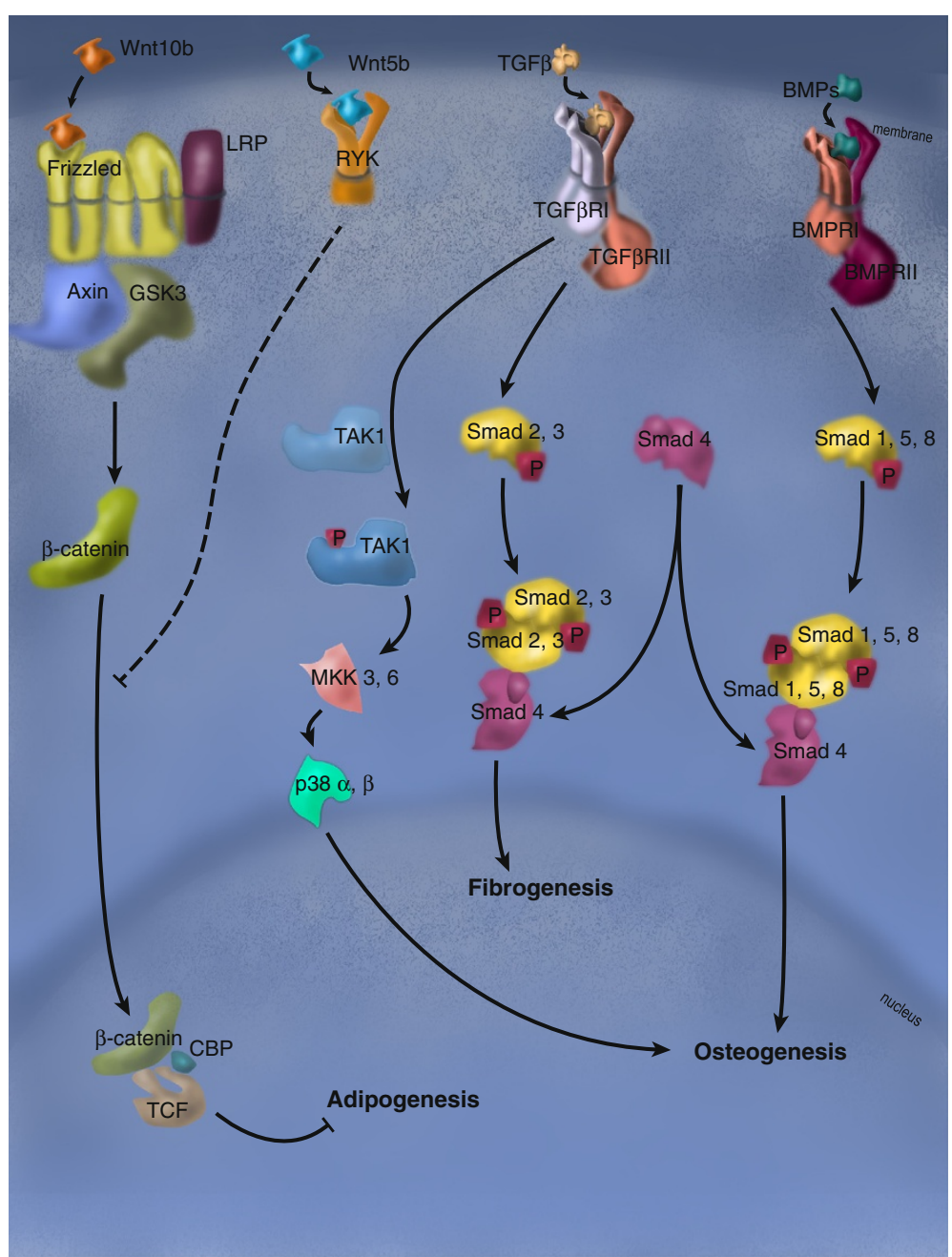

Figure 3 Signaling pathways driving mesenchymal stem cells to differentiate into lineages found in reparative disorders. While Wnt10b represses adipogenesis through the activity of B-catenin/TCF/Lef transcriptional complexes, activation of the non-canonical Wnt pathway by Wnt5b leads to repression of TCF/ $\beta$-catenin transcriptional activity and yields the opposite results. Non-canonical TGF $\beta$ signaling participates in bone formation through activation of the osteogenesis regulator Runx2. On the other hand, canonical TGF $\beta$ signaling plays a central role in the regulation of the fibrogenic gene program. The BMP signaling pathway drives osteogenesis through SMADs 1, 5, 8 and shares the SMAD4 component with the TGF $\beta$ pathway.

to regulate the activity of Runx2, a master transcriptional regulator that commands the expression of the osteogenic gene program, via Dlx5 [77]. In addition, Dlx5 also activates Osterix, a regulator of osteoblast maturation, independently of Runx2 activation [89].

Importantly, both the TGF $\beta$ and the BMP pathways connect with other signals that participate in bone formation. Components of the TGF $\beta$ signaling pathway interact with components of the pituitary hormone (PTH), Wnt and fibroblast growth factor (FGF) signaling pathways [90]. The BMP pathway, on the other hand, cross-talks with Notch, FGF and Wnt signaling [90]. Aberrant BMP signaling has been linked to heterotopic ossification, a pathological condition characterized by bone formation in skeletal muscle and soft tissues [40].
Mutations in the regulatory domain of the Alk2 receptor leading to hyper activation of the BMP signaling pathway have been shown to mimic the pathophysiology of fibrodysplasia ossificans progressive (FOP), an extreme form of heterotopic ossification [91]. Recent advances in the identification of the cellular substrate of FOP indicate that a muscle-resident $\mathrm{Lin}^{-} / \mathrm{Sca}-1^{+} / \mathrm{PDGFRa}^{+} / \mathrm{Tie}^{+}$ mesenchymal cell population can also adopt the osteogenic lineage upon induction with BMP2 [41]. Consistent with the previously discussed role of $\mathrm{Lin}^{-} / \mathrm{Sca}-$ $1^{+} / \mathrm{PDGFRa}^{+}$cells in SM fibro-fatty degeneration, the $\mathrm{Lin}^{-} / \mathrm{Sca}-1^{+} / \mathrm{PDGFRa}^{+} / \mathrm{Tie}^{+}$cells also generated ectopic adipocytes in the lesions induced by BMP2 injection [41].

The Wnt family comprises secreted cysteine-rich glycopeptides that act in a paracrine and autocrine manner 
through a so-called canonical B-catenin-dependent and/or a non-canonical B-catenin-independent pathway. MSCs have been reported to express several Wnt ligands, including Wnt2, Wnt4, Wnt5a, Wnt11 and Wnt16, along with Wnt receptors of the Frizzled (FZD) family FZD2, 3, 4, 5 and 6 , and co-receptors including LRP5 and 6. While the contribution of B-catenin-independent signaling on MSC activity is poorly understood, B-catenin-dependent signaling has been shown to play an important role in adipogenic and osteogenic differentiation of MSCs. Binding of Wnt to the FZD/LRP receptor complex induces the dissociation of the Axin/APC/GSK3B complex which, in the absence of Wnt signaling, phosphorylates B-catenin leading to its ubiquitination and degradation. Upon stabilization, B-catenin translocates into the nucleus, where it interacts with transcription factors of the lymphoid enhancer-binding factor/T-cell-specific factor (LEF/TCF) to induce the transcription of Wnt-regulated genes. Wnt molecules participate in adipogenic differentiation via the canonical B-catenin pathway. Wnt10b maintains preadipocytes undifferentiated by blocking the activity of the pro-adipogenic factors C/EBP $\alpha$ and PPAR $\gamma$ $[92,93]$. Indeed, transgenic mice overexpressing Wnt10b under the FABP4 promoter possess less adipose tissue in regular diet conditions and are resistant to diet-induced obesity. Those data were confirmed independently by overexpression of a dominant-negative form of TCF4 that facilitated adipogenic differentiation. Wnt5 also blocks PPAR $\gamma$ function, through a mechanism that involves H3K9 methylation [94]. In contrast to their inhibitory effect on adipogenesis, Wnt molecules induce osteogenic differentiation of MSCs. Osteogenic differentiation of MSCs - via a non-canonical pathway - with concomitant inhibition of adipogenic mechanisms has been shown to occur in MSCs $[95,96]$. The dual role of Wnt5 has also been shown in vivo, in the above-mentioned FABP4WNT10B transgenic mice, in which the reduction in fat tissue is accompanied by an increase in bone mass, and reduced bone loss [97]. Altogether, a pivotal role for the Wnt family can be proposed by which these molecules regulate the balance between adipogenic vs. osteogenic lineage in MSCs.

\section{Conclusions}

Reparative disorders are commonly accompanied with tissue injuries and subsequent repair processes. Stem cells are extremely important for tissue repair either by differentiating into new cells to replace damaged tissue (TSCs) or to aid in the regenerative or reparative process (MSCs). During the past decade, employment of various isolation and lineage-tracing methods both in vivo and in vitro has led to the identification of several types of adult tissue resident stem cells in distinct organs, and of a phenotypically homogeneous population of stromal progenitors present in all tissues analyzed and likely to be the in vivo equivalent of the ill-defined but often mentioned "mesenchymal stem cell". However, the draw back in many studies has been the presence of functional heterogeneity within stem cell populations, which hinders the generalized characterization or comparison of these cells across species and tissues to use in therapeutic settings. Overcoming this obstacle will likely require high throughput single cell analysis techniques that are just starting to be available. Apart from their well-established role in regeneration, TSCs may also contribute to fibrosis, fatty degeneration or heterotopic ossification. To what extent this happens, however, is as yet unknown, and overwhelming evidence implicates MSCs as the main culprits for most reparative disorders. In addition, recent findings fundamentally challenge the hypothesis that MSCs also derive from EMT or EndMT, and the existence of circulating fibrocytes, suggesting that local progenitors are the main cell type involved in repair. Although MSCs' participation in reparative disorders is proven, the molecular mechanisms by which they control the reparative process and regulate other cell types involved is critical for therapeutic intervention and in turn alter the fate choices of MSCs during repair. Promisingly, tissue resident MSCs have the potential to be included in cell-based therapies to treat reparative disorders as alternative autologous cell sources. Moreover, TGF $\beta$, BMP and Wnt signaling cascades are considered as key communication partners with other known signaling molecules in the regulation of MSCs and, therefore, viewed as potential therapeutic targets. To fruitfully deploy modulators of these pathways, however, the complexity of interaction of MSCs both at cellular and molecular levels need to be further elucidated.

\section{Abbreviations}

CFU-Fs: Colony forming unit - fibroblasts; ECM: Extracellular matrix; EMT: Epithelial-mesenchymal transition; EndMT: Endothelial-mesenchymal transition; FAPs: Fibro-adipogenic progenitors; FGF: Fibroblast growth factor: FZD: Frizzled; LEF/TCF: Lymphoid enhancer-binding factor/T-cell-specific factor; LR-MSCs: Lung derived/resident MSCs; MDSPCs: Muscle derived stem/ progenitor cells; MSCs: Mesenchymal stromal cells; SKPs: Skin-derived precursors; SMN: Survival of motor neuron; TGF: Transforming growth factor; TSCs: Tissue-specific resident stem cells.

\section{Competing interests}

The authors declare that they have no competing interests.

\section{Authors' contributions}

$T P, D R L, B P$ and $R H Z$ surveyed the literature and were involved in drafting the manuscript. $\mathrm{RHZ}$ was also responsible for formatting citations and the bibliography. FMR contributed through conception of content, supervision, correction and revision of the manuscript. All authors read and approved the final manuscript.

Received: 17 September 2012 Accepted: 29 November 2012 Published: 27 December 2012 


\section{References}

1. Gulliver G: On fatty degeneration of the arteries, with a note on some other fatty degenerations. Med Chir Trans 1843, 26:86-428.

2. Meryon E: On granular and fatty degeneration of the voluntary muscles. Med Chir Trans 1852, 35:73-84.

3. Gull WW, Sutton HG: On the pathology of the morbid state commonly called chronic Bright's disease with contracted kidney, ("arterio-capillary fibrosis."). Med Chir Trans 1872, 55:273-330.

4. Moyer AL, Wagner KR: Regeneration versus fibrosis in skeletal muscle. Curr Opin Rheumatol 2011, 23:568-573.

5. Quan TE, Cowper SE, Bucala R: The role of circulating fibrocytes in fibrosis. Curr Rheumatol Rep 2006, 8:145-150.

6. Hinz B, Gabbiani G: Fibrosis: recent advances in myofibroblast biology and new therapeutic perspectives. F1000 Biol Rep 2010, 2:78

7. Wallace GQ, McNally EM: Mechanisms of muscle degeneration, regeneration, and repair in the muscular dystrophies. Annu Rev Physiol 2009, 71:37-57.

8. Lucke C, Schindler K, Lehmkuhl L, Grothoff M, Eitel I, Schuler G, Thiele H, Kivelitz D, Gutberlet M: Prevalence and functional impact of lipomatous metaplasia in scar tissue following myocardial infarction evaluated by MRI. Eur Radiol 2010, 20:2074-2083.

9. Yerian L: Histopathological evaluation of fatty and alcoholic liver diseases. J Dig Dis 2011, 12:17-24.

10. Shore EM, Kaplan FS: Inherited human diseases of heterotopic bone formation. Nat Rev Rheumatol 2010, 6:518-527.

11. Pignolo R, Foley K: Nonhereditary heterotopic ossification. Implications for injury, arthropathy, and aging. Clin Rev Bone Miner Metabol 2005, 3:261-266.

12. Dominici M, Le Blanc K, Mueller I, Slaper-Cortenbach I, Marini F, Krause D, Deans R, Keating A, Prockop D, Horwitz E: Minimal criteria for defining multipotent mesenchymal stromal cells. The International Society for Cellular Therapy position statement. Cytotherapy 2006, 8:315-317.

13. Lindner U, Kramer J, Rohwedel J, Schlenke P: Mesenchymal stem or stromal cells: toward a better understanding of their biology? Transfus Med Hemother 2010, 37:75-83.

14. Weissman I: Stem cell therapies could change medicine... if they get the chance. Cell Stem Cell 2012, 10:663-665.

15. Maurer MH: Proteomic definitions of mesenchymal stem cells. Stem Cells Int 2011, 2011:704256

16. da Silva Meirelles $L$, Chagastelles PC, Nardi NB: Mesenchymal stem cells reside in virtually all post-natal organs and tissues. J Cell Sci 2006, 119:2204-2213.

17. Crisan M, Yap S, Casteilla L, Chen CW, Corselli M, Park TS, Andriolo G, Sun B, Zheng B, Zhang L, Norotte C, Teng PN, Traas J, Schugar R, Deasy BM, Badylak S, Buhring HJ, Giacobino JP, Lazzari L, Huard J, Peault B: A perivascular origin for mesenchymal stem cells in multiple human organs. Cell Stem Cell 2008, 3:301-313.

18. Caplan Al: All MSCs are pericytes? Cell Stem Cell 2008, 3:229-230.

19. Joe AW, Yi L, Natarajan A, Le Grand F, So L, Wang J, Rudnicki MA, Rossi FM: Muscle injury activates resident fibro/adipogenic progenitors that facilitate myogenesis. Nat Cell Biol 2010, 12:153-163.

20. Lemos DR, Paylor B, Chang C, Sampaio A, Underhill TM, Rossi FM: Functionally convergent white adipogenic progenitors of different lineages participate in a diffused system supporting tissue regeneration. Stem Cells 2012, 30:1152-1162

21. Festa E, Fretz J, Berry R, Schmidt B, Rodeheffer M, Horowitz M, Horsley V: Adipocyte lineage cells contribute to the skin stem cell niche to drive hair cycling. Cell 2011, 146:761-771.

22. Hinz B, Phan $\mathrm{SH}$, Thannickal VJ, Prunotto $\mathrm{M}$, Desmoulière $\mathrm{A}$, Varga J, De Wever O, Mareel M, Gabbiani G: Recent developments in myofibroblast biology: paradigms for connective tissue remodeling. Am J Pathol 2012, 180:1340-1355.

23. Carew RM, Wang B, Kantharidis P: The role of EMT in renal fibrosis. Cell Tissue Res 2012, 347:103-116.

24. Thiery JP, Acloque H, Huang RY, Nieto MA: Epithelial-mesenchymal transitions in development and disease. Cell 2009, 139:871-890.

25. Hass R, Otte A: Mesenchymal stem cells as all-round supporters in a normal and neoplastic microenvironment. Cell Commun Signal 2012, 10:26

26. Yi T, Song SU: Immunomodulatory properties of mesenchymal stem cells and their therapeutic applications. Arch Pharm Res 2012, 35:213-221.
27. Lin RZ, Moreno-Luna R, Zhou B, Pu WT, Melero-Martin JM: Equal modulation of endothelial cell function by four distinct tissue-specific mesenchymal stem cells. Angiogenesis 2012, 15:443-455.

28. Mathew SJ, Hansen JM, Merrell AJ, Murphy MM, Lawson JA, Hutcheson DA Hansen MS, Angus-Hill M, Kardon G: Connective tissue fibroblasts and Tcf4 regulate myogenesis. Development 2011, 138:371-384.

29. Segev E, Shefer G, Adar R, Chapal-llani N, Itzkovitz S, Horovitz I, Reizel Y, Benayahu D, Shapiro E: Muscle-bound primordial stem cells give rise to myofiber-associated myogenic and non-myogenic progenitors. PLoS One 2011, 6:e25605.

30. Nombela-Arrieta C, Ritz J, Silberstein LE: The elusive nature and function of mesenchymal stem cells. Nat Rev Mol Cell Biol 2011, 12:126-131.

31. Uezumi A, Fukada S, Yamamoto N, Takeda S, Tsuchida K: Mesenchymal progenitors distinct from satellite cells contribute to ectopic fat cell formation in skeletal muscle. Nat Cell Biol 2010, 12:143-152.

32. Lavasani M, Robinson AR, Lu A, Song M, Feduska JM, Ahani B, Tilstra JS, Feldman $\mathrm{CH}$, Robbins PD, Niedernhofer $\amalg$, Huard J: Muscle-derived stem/ progenitor cell dysfunction limits healthspan and lifespan in a murine progeria model. Nat Commun 2012, 3:608.

33. Rodeheffer MS: Tipping the scale: muscle versus fat. Nat Cell Biol 2010, 12:102-104

34. Paylor B, Natarajan A, Zhang RH, Rossi F: Nonmyogenic cells in skeletal muscle regeneration. Curr Top Dev Biol 2011, 96:139-165.

35. Uezumi A, Ito T, Morikawa D, Shimizu N, Yoneda T, Segawa M, Yamaguchi M, Ogawa R, Matev MM, Miyagoe-Suzuki Y, Takeda S, Tsujikawa K, Tsuchida $\mathrm{K}$, Yamamoto H, Fukada S: Fibrosis and adipogenesis originate from a common mesenchymal progenitor in skeletal muscle. J Cell Sci 2011 , 124:3654-3664.

36. Natarajan A, Lemos DR, Rossi FM: Fibro/adipogenic progenitors: a doubleedged sword in skeletal muscle regeneration. Cell Cycle 2010, 9:20452046

37. Nesti LJ, Jackson WM, Shanti RM, Koehler SM, Aragon AB, Bailey JR, Sracic MK, Freedman BA, Giuliani JR, Tuan RS: Differentiation potential of multipotent progenitor cells derived from war-traumatized muscle tissue. J Bone Joint Surg Am 2008, 90:2390-2398.

38. Jackson WM, Aragon AB, Bulken-Hoover JD, Nesti L, Tuan RS: Putative heterotopic ossification progenitor cells derived from traumatized muscle. J Orthop Res 2009, 27:1645-1651.

39. Jackson WM, Lozito TP, Djouad F, Kuhn NZ, Nesti LJ, Tuan RS: Differentiation and regeneration potential of mesenchymal progenitor cells derived from traumatized muscle tissue. J Cell Mol Med 2011, 15:2377-2388

40. Kaplan FS, Glaser DL, Hebela N, Shore EM: Heterotopic ossification. J Am Acad Orthop Surg 2004, 12:116-125.

41. Wosczyna MN, Biswas AA, Cogswell CA, Goldhamer DJ: Multipotent progenitors resident in the skeletal muscle interstitium exhibit robust BMP-dependent osteogenic activity and mediate heterotopic ossification. J Bone Miner Res 2012, 27:1004-1017.

42. Buckingham M: Myogenic progenitor cells and skeletal myogenesis in vertebrates. Curr Opin Genet Dev 2006, 16:525-532.

43. Seale P, Sabourin LA, Girgis-Gabardo A, Mansouri A, Gruss P, Rudnicki MA: Pax7 is required for the specification of myogenic satellite cells. Cell 2000, 102:777-786.

44. Lepper C, Conway SJ, Fan CM: Adult satellite cells and embryonic muscle progenitors have distinct genetic requirements. Nature 2009, 460:627-631.

45. Murphy M, Kardon G: Origin of vertebrate limb muscle: the role of progenitor and myoblast populations. Curr Top Dev Biol 2011, 96:1-32.

46. Alexakis C, Partridge T, Bou-Gharios G: Implication of the satellite cell in dystrophic muscle fibrosis: a self-perpetuating mechanism of collagen overproduction. Am J Physiol Cell Physiol 2007, 293:C661-C669.

47. Le Grand F, Rudnicki M: Satellite and stem cells in muscle growth and repair. Development 2007, 134:3953-3957.

48. Hayhurst M, Wagner AK, Cerletti M, Wagers AJ, Rubin LL: A cellautonomous defect in skeletal muscle satellite cells expressing low levels of survival of motor neuron protein. Dev Biol 2012, 368:323-334.

49. Brack AS, Conboy MJ, Roy S, Lee M, Kuo CJ, Keller C, Rando TA: Increased Wnt signaling during aging alters muscle stem cell fate and increases fibrosis. Science 2007, 317:807-810

50. Ono $Y$, Sensui $H$, Okutsu S, Nagatomi R: Notch2 negatively regulates myofibroblastic differentiation of myoblasts. J Cell Physiol 2007. 210:358-369. 
51. Zhou L, Wang L, Lu L, Jiang P, Sun H, Wang H: Inhibition of miR-29 by TGF-beta-Smad3 signaling through dual mechanisms promotes transdifferentiation of mouse myoblasts into myofibroblasts. PLoS One 2012, 7:e33766.

52. McKay BR, Ogborn DI, Bellamy LM, Tarnopolsky MA, Parise G: Myostatin is associated with age-related human muscle stem cell dysfunction. FASEB J 2012, 26:2509-2521.

53. Pelekanos RA, Li J, Gongora M, Chandrakanthan V, Scown J, Suhaimi N, Brooke G, Christensen ME, Doan T, Rice AM, Osborne GW, Grimmond SM, Harvey RP, Atkinson K, Little MH: Comprehensive transcriptome and immunophenotype analysis of renal and cardiac MSC-like populations supports strong congruence with bone marrow MSC despite maintenance of distinct identities. Stem Cell Res 2012, 8:58-73.

54. Martinu T, Palmer SM, Ortiz LA: Lung-resident mesenchymal stromal cells. A new player in post-transplant bronchiolitis obliterans syndrome? Am J Respir Crit Care Med 2011, 183:968-970.

55. Lama VN, Smith L, Badri L, Flint A, Andrei AC, Murray S, Wang Z, Liao H, Toews GB, Krebsbach PH, Peters-Golden M, Pinsky DJ, Martinez FJ, Thannickal VJ: Evidence for tissue-resident mesenchymal stem cells in human adult lung from studies of transplanted allografts. $J$ Clin Invest 2007, 117:989-996.

56. Walker N, Badri L, Wettlaufer S, Flint A, Sajjan U, Krebsbach PH, Keshamouni VG, Peters-Golden M, Lama VN: Resident tissue-specific mesenchymal progenitor cells contribute to fibrogenesis in human lung allografts. Am J Pathol 2011, 178:2461-2469.

57. Jun D, Garat C, West J, Thorn N, Chow K, Cleaver T, Sullivan T, Torchia EC, Childs C, Shade T, Tadjali M, Lara A, Nozik-Grayck E, Malkoski S, Sorrentino B, Meyrick B, Klemm D, Rojas M, Wagner DH Jr, Majka SM: The pathology of bleomycin-induced fibrosis is associated with loss of resident lung mesenchymal stem cells that regulate effector T-cell proliferation. Stem Cells 2011, 29:725-735.

58. Bonner JC: Mesenchymal cell survival in airway and interstitial pulmonary fibrosis. Fibrogenesis Tissue Repair 2010, 3:15.

59. Kalluri R, Weinberg RA: The basics of epithelial-mesenchymal transition. Clin Invest 2009, 119:1420-1428.

60. Fragiadaki M, Mason RM: Epithelial-mesenchymal transition in renal fibrosis - evidence for and against. Int J Exp Pathol 2011, 92:143-150.

61. Kriz W, Kaissling B, Le Hir M: Epithelial-mesenchymal transition (EMT) in kidney fibrosis: fact or fantasy? J Clin Invest 2011, 121:468-474.

62. Wells RG: The epithelial-to-mesenchymal transition in liver fibrosis: here today, gone tomorrow? Hepatology 2010, 51:737-740.

63. Chen YT, Chang FC, Wu CF, Chou YH, Hsu HL, Chiang WC, Shen J, Chen YM, Wu KD, Tsai TJ, Duffield JS, Lin SL: Platelet-derived growth factor receptor signaling activates pericyte-myofibroblast transition in obstructive and post-ischemic kidney fibrosis. Kidney Int 2011, 80:1170-1181.

64. Humphreys BD, Lin SL, Kobayashi A, Hudson TE, Nowlin BT, Bonventre JV, Valerius MT, McMahon AP, Duffield JS: Fate tracing reveals the pericyte and not epithelial origin of myofibroblasts in kidney fibrosis. Am J Pathol 2010, 176:85-97.

65. Lin SL, Kisseleva T, Brenner DA, Duffield JS: Pericytes and perivascular fibroblasts are the primary source of collagen-producing cells in obstructive fibrosis of the kidney. Am J Pathol 2008, 173:1617-1627.

66. Li L, Zepeda-Orozco D, Black R, Lin F: Autophagy is a component of epithelial cell fate in obstructive uropathy. Am J Pathol 2010, 176:1767-1778.

67. Scholten D, Osterreicher $\mathrm{CH}$, Scholten A, Iwaisako K, Gu G, Brenner DA, Kisseleva T: Genetic labeling does not detect epithelial-to-mesenchymal transition of cholangiocytes in liver fibrosis in mice. Gastroenterology 2010, 139:987-998

68. Taura K, Miura K, Iwaisako K, Osterreicher $\mathrm{CH}$, Kodama Y, Penz-Osterreicher M, Brenner DA: Hepatocytes do not undergo epithelial-mesenchymal transition in liver fibrosis in mice. Hepatology 2010, 51:1027-1036.

69. Rock JR, Barkauskas CE, Cronce MJ, Xue Y, Harris JR, Liang J, Noble PW, Hogan BL: Multiple stromal populations contribute to pulmonary fibrosis without evidence for epithelial to mesenchymal transition. Proc Natl Acad Sci U S A 2011, 108:E1475-E1483.

70. Boye K, Maelandsmo GM: S100A4 and metastasis: a small actor playing many roles. Am J Pathol 2010, 176:528-535.

71. Zeisberg EM, Tarnavski O, Zeisberg M, Dorfman AL, McMullen JR, Gustafsson E, Chandraker A, Yuan X, Pu WT, Roberts AB, Neilson EG, Sayegh MH, Izumo $S$, Kalluri R: Endothelial-to-mesenchymal transition contributes to cardiac fibrosis. Nat Med 2007, 13:952-961.
72. Bucala R, Spiegel LA, Chesney J, Hogan M, Cerami A: Circulating fibrocytes define a new leukocyte subpopulation that mediates tissue repair. Mol Med 1994, 1:71-81.

73. Bellini A, Mattoli S: The role of the fibrocyte, a bone marrow-derived mesenchymal progenitor, in reactive and reparative fibroses. Lab Invest 2007, 87:858-870.

74. Pichler M, Rainer PP, Schauer S, Hoefler G: Cardiac fibrosis in human transplanted hearts is mainly driven by cells of intracardiac origin. $J \mathrm{Am}$ Coll Cardiol 2012, 59:1008-1016.

75. Barisic-Dujmovic T, Boban I, Clark SH: Fibroblasts/myofibroblasts that participate in cutaneous wound healing are not derived from circulating progenitor cells. J Cell Physiol 2010, 222:703-712.

76. Derynck R, Akhurst RJ: Differentiation plasticity regulated by TGF-beta family proteins in development and disease. Nat Cell Biol 2007, 9:1000-1004.

77. Shi Y, Massague J: Mechanisms of TGF-beta signaling from cell membrane to the nucleus. Cell 2003, 113:685-700.

78. Matsunobu T, Torigoe $K$, Ishikawa M, de Vega S, Kulkarni AB, Iwamoto $Y$, Yamada $Y$ : Critical roles of the TGF-beta type I receptor ALK5 in perichondrial formation and function, cartilage integrity, and osteoblast differentiation during growth plate development. Dev Biol 2009, 332:325-338.

79. Petruschke T, Röhrig K, Hauner $\mathrm{H}$ : Transforming growth factor beta (TGF-beta) inhibits the differentiation of human adipocyte precursor cells in primary culture. Int J Obes Relat Metab Disord 1994, 18:532-536.

80. Choy L, Derynck R: Transforming growth factor-beta inhibits adipocyte differentiation by Smad3 interacting with CCAAT/enhancer-binding protein (C/EBP) and repressing C/EBP transactivation function. J Biol Chem 2003, 278:9609-9619.

81. Oshimori N, Fuchs E: Paracrine TGF-beta signaling counterbalances BMPmediated repression in hair follicle stem cell activation. Cell Stem Cell 2012, 10:63-75.

82. Kim WJ: Cellular signaling in tissue regeneration. Yonsei Med J 2000, 41:692-703.

83. Kawase $Y$, Yanagi $Y$, Takato T, Fujimoto M, Okochi H: Characterization of multipotent adult stem cells from the skin: transforming growth factorbeta (TGF-beta) facilitates cell growth. Exp Cell Res 2004, 295:194-203.

84. Vidal B, Serrano AL, Tjwa M, Suelves M, Ardite E, De Mori R, Baeza-Raja B, Martinez de Lagran M, Lafuste P, Ruiz-Bonilla V, Jardi M, Gherardi R, Christov C, Dierssen M, Carmeliet P, Degen JL, Dewerchin M, Munoz-Canoves P: Fibrinogen drives dystrophic muscle fibrosis via a TGFbeta/alternative macrophage activation pathway. Genes Dev 2008, 22:1747-1752.

85. Ardite E, Perdiguero E, Vidal B, Gutarra S, Serrano AL, Munoz-Canoves P: PAl1-regulated miR-21 defines a novel age-associated fibrogenic pathway in muscular dystrophy. J Cell Biol 2012, 196:163-175.

86. Bandyopadhyay A, Tsuji K, Cox K, Harfe BD, Rosen V, Tabin CJ: Genetic analysis of the roles of BMP2, BMP4, and BMP7 in limb patterning and skeletogenesis. PLOS Genet 2006, 2:e216.

87. Zhou Z, Xie J, Lee D, Liu Y, Jung J, Zhou L, Xiong S, Mei L, Xiong WC: Neogenin regulation of BMP-induced canonical Smad signaling and endochondral bone formation. Dev Cell 2010, 19:90-102.

88. Fukuda T, Scott G, Komatsu Y, Araya R, Kawano M, Ray MK, Yamada M, Mishina Y: Generation of a mouse with conditionally activated signaling through the BMP receptor, ALK2. Genesis 2006, 44:159-167.

89. Lee MH, Kwon TG, Park HS, Wozney JM, Ryoo HM: BMP-2-induced Osterix expression is mediated by Dlx 5 but is independent of Runx2. Biochem Biophys Res Commun 2003, 309:689-694.

90. Chen G, Deng C, Li YP: TGF-beta and BMP signaling in osteoblast differentiation and bone formation. Int J Biol Sci 2012, 8:272-288.

91. Fukuda T, Kohda M, Kanomata K, Nojima J, Nakamura A, Kamizono J, Noguchi Y, Iwakiri K, Kondo T, Kurose J, Endo K, Awakura T, Fukushi J, Nakashima Y, Chiyonobu T, Kawara A, Nishida Y, Wada I, Akita M, Komori T, Nakayama K, Nanba A, Maruki Y, Yoda T, Tomoda H, Yu PB, Shore EM, Kaplan FS, Miyazono K, Matsuoka M, et al: Constitutively activated ALK2 and increased SMAD1/5 cooperatively induce bone morphogenetic protein signaling in fibrodysplasia ossificans progressiva. J Biol Chem 2009, 284:7149-7156.

92. Ross SE, Hemati N, Longo KA, Bennett CN, Lucas PC, Erickson RL, MacDougald OA: Inhibition of adipogenesis by Wnt signaling. Science 2000, 289:950-953.

93. Kawai M, Mushiake S, Bessho K, Murakami M, Namba N, Kokubu C, Michigami T, Ozono K: Wnt/Lrp/beta-catenin signaling suppresses 
adipogenesis by inhibiting mutual activation of PPARgamma and C/ EBPalpha. Biochem Biophys Res Commun 2007, 363:276-282.

94. Takada I, Mihara M, Suzawa M, Ohtake F, Kobayashi S, Igarashi M, Youn MY, Takeyama K, Nakamura T, Mezaki Y, Takezawa S, Yogiashi Y, Kitagawa H, Yamada G, Takada S, Minami Y, Shibuya H, Matsumoto K, Kato S: A histone lysine methyltransferase activated by non-canonical Wnt signalling suppresses PPAR-gamma transactivation. Nat Cell Biol 2007, 9:1273-1285.

95. Bilkovski R, Schulte DM, Oberhauser F, Gomolka M, Udelhoven M, Hettich MM, Roth B, Heidenreich A, Gutschow C, Krone W, Laudes M: Role of WNT$5 \mathrm{a}$ in the determination of human mesenchymal stem cells into preadipocytes. J Biol Chem 2010, 285:6170-6178.

96. Santos A, Bakker AD, de Blieck-Hogervorst JM, Klein-Nulend J: WNT5A induces osteogenic differentiation of human adipose stem cells via rhoassociated kinase ROCK. Cytotherapy 2010, 12:924-932.

97. Bennett CN, Longo KA, Wright WS, Suva LJ, Lane TF, Hankenson KD, MacDougald OA: Regulation of osteoblastogenesis and bone mass by Wnt10b. Proc Natl Acad Sci U S A 2005, 102:3324-3329.

doi:10.1186/1755-1536-5-20

Cite this article as: Pretheeban et al: Role of stem/progenitor cells in reparative disorders. Fibrogenesis \& Tissue Repair 2012 5:20.

\section{Submit your next manuscript to BioMed Central and take full advantage of:}

- Convenient online submission

- Thorough peer review

- No space constraints or color figure charges

- Immediate publication on acceptance

- Inclusion in PubMed, CAS, Scopus and Google Scholar

- Research which is freely available for redistribution 